\title{
Continued inhibition of structural damage over 2 years in patients with rheumatoid arthritis treated with rituximab in combination with methotrexate
}

\author{
Stanley B Cohen, ${ }^{1}$ Edward Keystone, ${ }^{2}$ Mark C Genovese, ${ }^{3}$ Paul Emery, ${ }^{4}$ Charles Peterfy, ${ }^{5}$ \\ Paul Peter Tak, ${ }^{6}$ Matt Cravets, ${ }^{7}$ Tim Shaw $^{8}$ David Hagerty ${ }^{7}$
}

${ }^{1}$ Metroplex Clinical Research Center, Dallas, Texas, USA

2University of Toronto, Toronto, Canada

${ }^{3}$ Stanford University, Palo Alto, California, USA

${ }^{4}$ Leeds General Infirmary, Leeds, UK

${ }^{5}$ Synarc, San Francisco,

California, USA

${ }^{6} \mathrm{AMC} /$ University of Amsterdam, Amsterdam, The Netherlands ${ }^{7}$ Biogen Idec, Inc, San Diego, California, USA

${ }^{8}$ Roche Products Ltd, Welwyn

Garden City, UK

\section{Correspondence to}

Dr S B Cohen, Metroplex Clinical Research Center, Dallas, Texas, USA;

scohen@arthdocs.com

Accepted 19 November 2009

\section{ABSTRACT}

Background Rituximab inhibited structural damage at 1 year in patients with rheumatoid arthritis (RA) who had had a previous inadequate response to tumour necrosis factor (TNF) inhibitors.

Objective To assess structural damage progression through 2 years.

Methods Intention-to-treat patients with one postbaseline radiograph (rituximab $n=281$; placebo $n=187$ ) received background methotrexate (MTX) and were randomised to rituximab $(2 \times 1000 \mathrm{mg}$ infusions, 2 weeks apart) or placebo; patients were eligible for rituximab re-treatment every 6 months. By week 104, 82\% of the placebo population had received $\geq 1$ dose of rituximab. Radiographic end points included the change in total Sharp score (TSS), erosion and joint space narrowing scores at week 104.

Results At week 104, significantly lower changes in TSS (1.14 vs $2.81 ; p<0.0001)$, erosion score (0.72 vs $1.80 ; p<0.0001)$ and joint space narrowing scores $(0.42$ vs 1.00; $p<0.0009$ ) were observed with rituximab plus MTX vs placebo plus MTX. Within the rituximab group, $87 \%$ who had no progression of joint damage at 1 year remained non-progressive at 2 years.

Conclusions Rituximab plus MTX demonstrated significant and sustained effects on joint damage progression in patients with RA and a previously inadequate response to TNF inhibitors.

\section{INTRODUCTION}

Before the development of targeted biological treatments, irreversible joint damage and deformity leading to a progressive decline in functional status and increased work disability were common outcomes for patients with rheumatoid arthritis (RA). ${ }^{12}$ Biological treatments that inhibit tumour necrosis factor $\alpha$ (TNF $\alpha)$, T-cell costimulation or interleukin 6 have demonstrated the ability to inhibit radiographic progression in patients with either early or longstanding disease..$^{3-8}$

Rituximab, a monoclonal antibody that selectively targets CD20-positive B cells, reduces the signs and symptoms of RA and has been proved to inhibit joint damage progression over 1 year in patients with RA for whom TNF inhibitors produced an inadequate response. ${ }^{910}$ Here we report the sustained effects of rituximab on the progression of joint damage over an extended period of 2 years.

\section{PATIENTS AND METHODS}

\section{Patients}

Patients in this post hoc analysis were participants in the phase III REFLEX study. ${ }^{9}$ Eligibility criteria for
REFLEX have been described previously. ${ }^{9}$ Briefly, patients were included if they had active RA despite treatment with methotrexate (MTX) $\geq 10 \mathrm{mg} /$ week and had experienced an inadequate response (lack of efficacy or intolerance) to at least one TNF inhibitor.

The study was performed in accordance with the Declaration of Helsinki. All participating sites received approval from their governing institutional review board (or equivalent) and all patients provided written informed consent.

\section{Study protocol}

REFLEX was a randomised, double-blind, placebocontrolled, phase III study with an option for further treatment courses under a separate extension study. Patients continued background MTX and were randomly assigned to placebo or rituximab (MabThera, Roche, Welwyn Garden City, UK; Rituxan, Genentech, South San Francisco, California, USA and Biogen Idec, San Diego, California, USA). Rituximab 1000 mg was administered by intravenous infusion on days 1 and 15. All patients received corticosteroid treatment, consisting of intravenous methylprednisolone $100 \mathrm{mg}$ before each infusion and oral prednisone during the 2 -week treatment period (60 mg on days $2-7,30 \mathrm{mg}$ on days 8-14).

From weeks 16 to 24 , patients who failed to respond to treatment could receive rescue therapy. Patients randomised to placebo could receive rituximab and patients randomised to rituximab could receive standard care. Patients completing week 24 were eligible to receive further courses of rituximab within an open-label extension study. Further courses of rituximab were also available for placebo patients who had responded to rescue treatment.

Radiographs of hands, wrists (posterior/anterior) and feet (anterior/posterior) were performed at screening (baseline) and at weeks 24, 56 and 104, relative to randomisation. Radiographs were read at a central reading facility by two independent expert radiologists and scored using the Genantmodified Sharp scoring system. ${ }^{11} 12$ Radiologists were blinded to the treatment group assignment, chronological order of the radiographs and patients' clinical response.

\section{Radiographic outcome measures}

Radiographic assessments included the mean change in total Genant-modified Sharp score (mTSS), the erosion score, the joint space narrowing score and the proportion of patients with no further joint damage progression (defined as a change in mTSS $\leq 0$ ). All assessments compared 
baseline and week 104. Radiographic changes were also determined during discrete time intervals of baseline to 24 weeks, 24-56 weeks and 56-104 weeks. The annualised progression rate (APR) was calculated to provide a measure of the rate of change in progression standardised to a common time interval. The APR for each patient was calculated as follows:

$$
\mathrm{APR}=364 \times \frac{\text { Score }_{\text {time2 }}-\text { Score }_{\text {time1 }}}{\text { StudyDay }_{\text {time2 }}-\text { StudyDay }_{\text {time1 }}}
$$

\section{Statistical analysis}

The primary population for the radiographic analysis was defined as all patients (including those withdrawing or receiving rescue) included in the REFLEX intention-to-treat (ITT) population who had at least one post-baseline radiograph (either 24, 56 or 104 weeks). All missing data were imputed using linear extrapolation of the progression observed from baseline to the week 24/week 56 radiographs. Analyses were conducted using a non-parametric analysis (Van Elteren test), stratified by region (USA vs non-USA) and baseline rheumatoid factor (positive vs negative). In addition, sensitivity analyses were conducted using observed data only.

\section{RESULTS}

\section{Patient characteristics and disposition}

A total of 517 patients were randomised: 308 to rituximab plus MTX and 209 to placebo plus MTX. Of these, 468 patients (281 rituximab patients and 187 placebo patients) were included in the REFLEX ITT population, and had a baseline film at screening and at least one post-baseline radiograph. A total of 197 rituximab and 135 placebo patients had radiographs at both baseline and week 104. The baseline characteristics and measures of disease activity were similar in both treatment groups and were similar to those of the original ITT population (table 1).

By week 104, 165/281 patients (59\%) in the rituximab group had received two or more courses of rituximab. Of the 187 patients randomised to placebo, 154 (82\%) had received at least one dose of rituximab before their last observed radiograph, with $94(50 \%)$ having received two or more courses. Only 33 patients $(18 \%)$ initially randomised to placebo did not receive rituximab treatment.

\section{Radiographic efficacy}

The mean change in the mTSS from baseline to 104 weeks was significantly lower in the rituximab group than in the placebo group (1.14 vs 2.81, respectively; $\mathrm{p}<0.0001)$. Significant

Table 1 Baseline demographic characteristics of the patients*

\begin{tabular}{lcc}
\hline Characteristics & $\begin{array}{c}\text { Placebo plus } \\
\text { MTX (n=187) }\end{array}$ & $\begin{array}{c}\text { Rituximab plus } \\
\text { MTX (n=281) }\end{array}$ \\
\hline Female/male (n (\%)) & $150(80) / 37(20)$ & $228(81) / 53(19)$ \\
Age (years) & $52.9(12.1)$ & $52.5(12.2)$ \\
Disease duration (years) & $11.7(7.7)$ & $11.9(8.2)$ \\
Swollen joint count & $23.1(12.8)$ & $23.2(11.9)$ \\
Tender joint count & $33.2(15.7)$ & $33.2(15.1)$ \\
CRP (mg/dl) & $3.7(3.8)$ & $3.7(3.9)$ \\
Anti-CCP positive (n (\%)) & $82(44)$ & $130(46)$ \\
ESR (mm/h) & $48.7(26.5)$ & $47.8(25.6)$ \\
HAQ-DI score & $1.9(0.54)$ & $1.8(0.57)$ \\
Total Genant-modified Sharp score & $32.5(31.5)$ & $30.6(26.7)$ \\
\hline
\end{tabular}

*Except where indicated otherwise values are the mean (SD).

CCP, cyclic citrullinated peptide; CRP, C-reactive protein; ESR, erythrocyte sedimentation rate; HAO-DI, Health Assessment Questionnaire-Disability Index; MTX, methotrexate. differences in the mean change in erosion and joint space narrowing scores were also observed (figure 1).

The proportion of patients with no progression in joint damage over 2 years was significantly higher in the rituximab group than in the placebo group (57\% vs $39 \%$, respectively; $p<0.0001$; figure 2A). Similarly, a higher proportion of patients randomised to rituximab had no change in erosion scores over the 2 years compared with patients randomised to placebo (60\% vs $44 \%$, respectively; $\mathrm{p}=0.0003$; figure $2 \mathrm{~B}$ ). Sensitivity analyses using observed data were consistent with the primary analyses.

Over discrete time intervals, the rate and extent of progression of joint damage in patients randomised to rituximab remained consistent. The rituximab group exhibited consistent mean changes in the mTSS during the first and second years, while the placebo group - most of whom had by then received rituximab-showed slower rates of change during their second year (figure 2C). Similarly, whereas in the rituximab group the APR remained consistent, in the placebo group it gradually declined from 1.60 points/year during the initial 24-week period to 0.93 points/year in the second year (figure 2D).

The proportion of patients with no change in their mTSS (figure 2A) and with no new erosions increased during each time period in each treatment group (figure $2 \mathrm{~B}$ ). Of those patients randomised to rituximab who did not progress during the first year, $87 \%$ did not progress during the second year either.

\section{DISCUSSION}

Inhibition of structural joint damage by rituximab in patients with with RA and a previous inadequate response to TNF inhibitors was first described over a 1 -year period. ${ }^{10}$ Here we have demonstrated that the initial effects of rituximab are maintained over an extended interval of 2 years, with all measures of joint damage significantly improved compared with placebo plus MTX.

Treatment with rituximab was associated with a significantly higher proportion of patients with no progression of joint damage over the 2 years compared with placebo plus MTX. The proportion of patients with no progression (57\%) achieved with rituximab treatment compares well with that seen with other

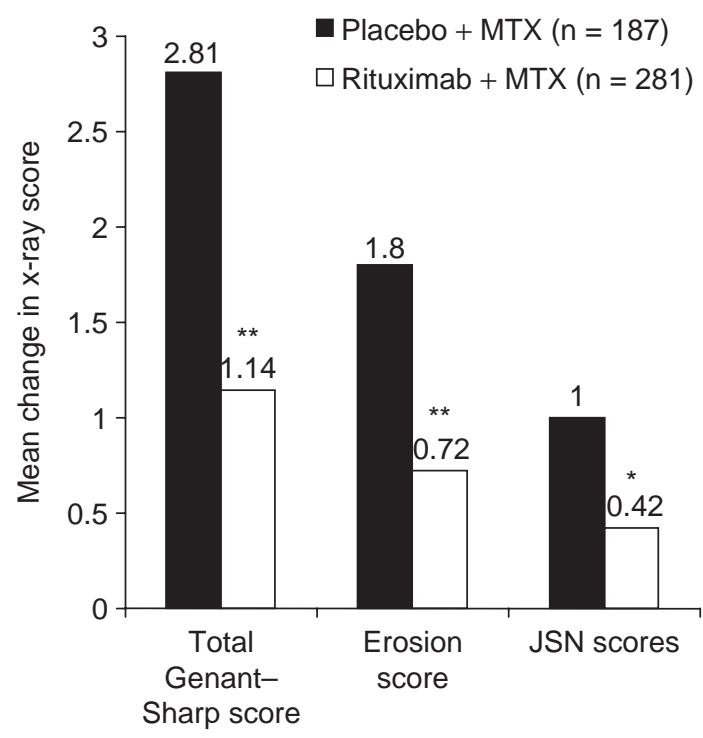

Figure 1 Changes from baseline to 2 years in total Genant-modified Sharp, erosion and joint space narrowing (JSN) scores in patients treated with rituximab $(2 \times 1000 \mathrm{mg})$ plus methotrexate $(\mathrm{MTX})$ or placebo plus MTX ${ }^{*} \mathrm{p}<0.005$; ${ }^{*} \mathrm{p}<0.0001$ versus placebo plus MTX. 

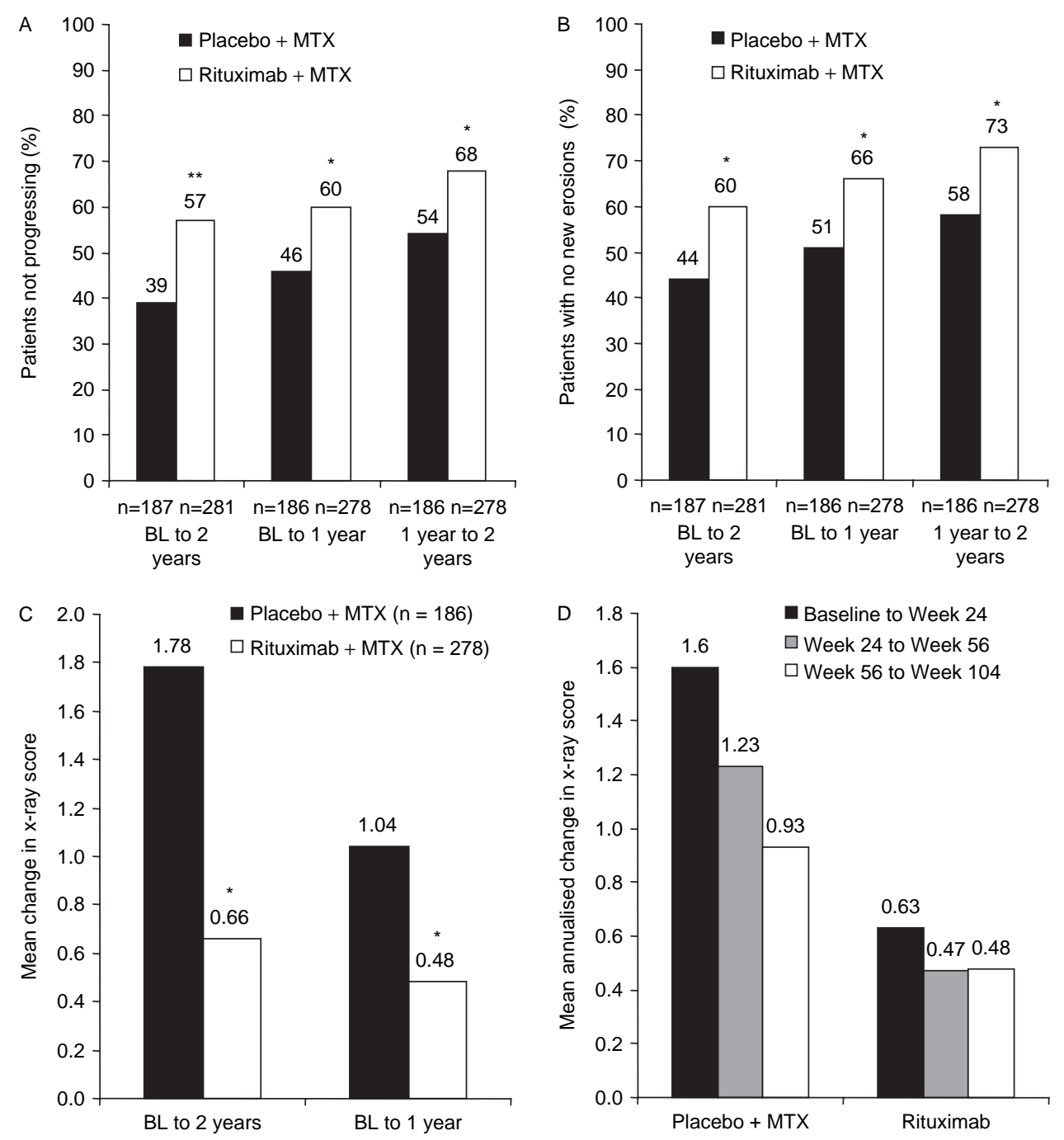

Figure 2 (A) Proportion of patients not progressing over the duration of the study. (B) Proportion of patients with no new erosions over the duration of the study. (C) Treatment effect of placebo plus MTX and rituximab $(2 \times 1000 \mathrm{mg})$ plus MTX on total Genant-modified Sharp score. (D) Annualised rate of progression in total Genant-modified Sharp score. BL, baseline; MTX, methotrexate ${ }^{*} p<0.005 ;{ }^{* *} p<0.0001$.

treatments with biological agents, albeit in less treatment-refractory patient populations. ${ }^{6} 1314$ Importantly, of those rituximab patients with no progression in the first year, $87 \%$ maintained a non-progressive status during the second year.

Although patients were initially randomised to either rituximab or placebo, $82 \%$ of placebo patients had switched to rituximab by 2 years. The impact of this switch on the progression of joint damage in this placebo-rituximab group is evident by the reduced changes in scores between time periods and the gradual slowing in their APR. The consequence of this switch to active treatment is that the degree of progression observed in the 'placebo' group is less than would have been observed had those patients been maintained solely on MTX, thereby underestimating the relative treatment effect. The extent of this discrepancy can be estimated using the method devised by Strand and Sharp ${ }^{15}$ for estimating APRs. By dividing the baseline mean mTSS (32.5) by the mean disease duration (11.7), the predicted progression for the placebo group over 2 years was 5.55. However, the observed progression was much lower (2.81), suggesting that the switch to rituximab had a large influence on the progression of joint damage in this control group. Consequently, the relative treatment effect size cannot be accurately measured. Nevertheless, using the predicted and observed progression in the placebo group a reduction in joint damage of $59-79 \%$ for rituximab plus MTX compared with placebo plus MTX could be estimated. Given the estimated nature of this effect, together with the lack of available radiographic data in similar patient populations, comparisons of this effect size with other biological agents used for RA would not be appropriate.

In conclusion, this 2-year analysis demonstrates that rituximab plus MTX has significant and sustained effects on the inhibition of joint damage in a population of patients with active RA who had previously experienced an inadequate response to TNF inhibitors.

Acknowledgements Writing assistance was provided by Claire Snowball (Adelphi Communications Ltd) in consultation with the authors, Roche Products Ltd and Genentech.

Funding This study was sponsored by F Hoffmann-La Roche Ltd, Genentech, Inc and Biogen Idec, Inc. A portion of this work (Stanford University) was supported in part by a grant from the National Institutes of Health National Center for Research Resources (5 M01 RR000070).

Competing interests SC has received consulting and speaker fees and research grants from Genentech and Biogen Idec. PE and PPT have received consulting and speaker fees and research grants from Roche. EK has received consulting and speaker fees from Roche and Genentech and research grants from Roche. MCG has received speaker fees and research grant support from Roche and has served as a consultant for Roche, Biogen Idec and Genentech. DH and MWC are employees of Biogen Idec. TS is an employee and owns shares in Roche Products Ltd. CP has received 
consulting and speaker fees from Genentech and Biogen Idec and is an employee of Synarc Inc.

Ethics approval This study was conducted with the approval of the protocol for this study and any accompanying material provided to the patient (eg, patient information sheets and descriptions of the study used to obtain informed consent) were submitted by the investigator to the associated independent ethics committee (IEC) or institutional review board (IRB). Approval from the committee was obtained before starting the study, and was documented in a letter to the investigator specifying the date on which the committee met and granted the approval. Any modifications made to the protocol after receipt of the IEC/IRB approval were also to be submitted by the investigator to the committee in accordance with local procedures and regulatory requirements.

\section{REFERENCES}

1. Pincus T, Callahan LF. The 'side effects' of rheumatoid arthritis: joint destruction, disability and early mortality. Br J Rheumatol 1993;32(Suppl 1):28-37.

2. Pincus T, Callahan LF, Sale WG, et al. Severe functional declines, work disability, and increased mortality in seventy-five rheumatoid arthritis patients studied over nine years. Arthritis Rheum 1984;27:864-72.

3. Breedveld FC, Weisman MH, Kavanaugh AF, et al. The PREMIER study: a multicenter, randomized, double-blind clinical trial of combination therapy with adalimumab plus methotrexate versus methotrexate alone or adalimumab alone in patients with early, aggressive rheumatoid arthritis who had not had previous methotrexate treatment. Arthritis Rheum 2006;54:26-37.

4. St Clair EW, van der Heijde DM, Smolen JS, et al. Combination of infliximab and methotrexate therapy for early rheumatoid arthritis: a randomized, controlled trial. Arthritis Rheum 2004;50:3432-43.

5. Klareskog L, van der Heijde D, de Jager JP, et al. Therapeutic effect of the combination of etanercept and methotrexate compared with each treatment alone in patients with rheumatoid arthritis: double-blind randomised controlled trial. Lancet 2004;363:675-81.
6. Keystone EC, Kavanaugh AF, Sharp JT, et al. Radiographic, clinical, and functional outcomes of treatment with adalimumab (a human anti-tumor necrosis factor monoclonal antibody) in patients with active rheumatoid arthritis receiving concomitant methotrexate therapy: a randomized, placebo-controlled, 52-week trial. Arthritis Rheum 2004;50:1400-11.

7. Nishimoto N, Hashimoto J, Miyasaka N, et al. Study of active controlled monotherapy used for rheumatoid arthritis, an IL-6 inhibitor (SAMURAI): evidence of clinical and radiographic benefit from an $\mathrm{x}$ ray reader-blinded randomised controlled trial of tocilizumab. Ann Rheum Dis 2007;66:1162-7.

8. Kremer JM, Genant HK, Moreland LW, et al. Effects of abatacept in patients with methotrexate-resistant active rheumatoid arthritis: a randomized trial. Ann Intern Med 2006; 144:865-76.

9. Cohen SB, Emery P, Greenwald MW, et al. Rituximab for rheumatoid arthritis refractory to anti-tumor necrosis factor therapy: Results of a multicenter, randomized, double-blind, placebo-controlled, phase III trial evaluating primary efficacy and safety at twenty-four weeks. Arthritis Rheum 2006;54:2793-806.

10. Keystone E, Emery P, Peterfy CG, et al. Rituximab inhibits structural joint damage in patients with rheumatoid arthritis with an inadequate response to tumour necrosis factor inhibitor therapies. Ann Rheum Dis 2009;68:216-21.

11. Genant HK. Methods of assessing radiographic change in rheumatoid arthritis. Am J Med 1983;75(6A):35-47.

12. Genant HK, Jiang Y, Peterfy C, et al. Assessment of rheumatoid arthritis using a modified scoring method on digitized and original radiographs. Arthritis Rheum 1998; 41:1583-90.

13. Genant HK, Peterfy CG, Westhovens R, et al. Abatacept inhibits progression of structural damage in rheumatoid arthritis: results from the long-term extension of the AlM trial. Ann Rheum Dis 2008;67:1084-9.

14. Genovese MC, Bathon JM, Fleischmann RM, et al. Longterm safety, efficacy, and radiographic outcome with etanercept treatment in patients with early rheumatoid arthritis. J Rheumatol 2005;32:1232-42.

15. Strand V, Sharp JT. Radiographic data from recent randomized controlled trials in rheumatoid arthritis: what have we learned? Arthritis Rheum 2003:48:21-34. 


\section{Corrections}

The department of one of the authors who co-authored all of the below papers has found that the affiliations were not correct. The correct affiliations for Professor P Emery, for all of the below articles, are: ${ }^{1}$ Section of Musculoskeletal Disease, Leeds Institute of Molecular Medicine, University of Leeds; ${ }^{2}$ NIHR Leeds Musculoskeletal Biomedical Research Unit, Leeds Teaching Hospitals Trust, Leeds, UK.

1. Keystone E, Emery P, Peterfy CG, et al. Rituximab inhibits structural joint damage in patients with rheumatoid arthritis with an inadequate response to tumour necrosis factor inhibitor therapies. Ann Rheum Dis 2009;68:216-21.

2. Doward LC, McKenna SP, Whalley D, et al. The development of the L-OoL: a quality-of-life instrument specific to systemic lupus erythematosus. Ann Rheum Dis 2009;68:196-200.

3. Potter C, Hyrich KL, Tracey A, et al. Association of rheumatoid factor and anticyclic citrullinated peptide positivity, but not carriage of shared epitope or PTPN22 susceptibility variants, with anti-TNF response in RA. Ann Rheum Dis 2009;68:69-74.

4. Smolen JS, Han C, van der Heijde DM, et al.; Active-Controlled Study of Patients Receiving Infliximab for the Treatment of Rheumatoid Arthritis of Early Onset (ASPIRE) Study Group. Radiographic changes in rheumatoid arthritis patients attaining different disease activity states with methotrexate monotherapy and infliximab plus methotrexate: the impacts of remission and tumour necrosis factor blockade. Ann Rheum Dis 2009;68:823-7.

5. Buch MH, Boyle DL, Rosengren S, et al. Mode of action of abatacept in rheumatoid arthritis patients having failed tumour necrosis factor blockade: a histological, gene expression and dynamic magnetic resonance imaging pilot study. Ann Rheum Dis 2009;68:1220-7.

6. Emery P, Van Vollenhoven R, Ostergaard M, et al. Guidelines for initiation of antitumour necrosis factor therapy in rheumatoid arthritis: similarities and differences across Europe. Ann Rheum Dis 2009;68:456-9.

7. Bejarano V, Conaghan PG, Proudman SM, et al. Long-term efficacy and toxicity of ciclosporin A in combination with methotrexate in poor prognosis rheumatoid arthritis Ann Rheum Dis 2009;68:761-3.

8. Rudwaleit M, Landewé R, van der Heijde D, et al. The development of Assessment of SpondyloArthritis international Society classification criteria for axial spondyloarthritis (part I): classification of paper patients by expert opinion including uncertainty appraisal. Ann Rheum Dis 2009;68:770-6.

9. Bennett AN, Marzo-Ortega H, Emery P, et al.; Leeds Spondyloarthropathy Group. Diagnosing axial spondyloarthropathy. The new Assessment in SpondyloArthritis international Society criteria: MRI entering centre stage. Ann Rheum Dis 2009;68:765-7.

10. Marzo-Ortega H, McGonagle D, O'Connor P, et al. Baseline and 1-year magnetic resonance imaging of the sacroiliac joint and lumbar spine in very early inflammatory back pain. Relationship between symptoms, HLA-B27 and disease extent and persistence. Ann Rheum Dis 2009;68:1721-7.

11. Gilworth G, Emery P, Gossec L, et al. Adaptation and cross-cultural validation of the rheumatoid arthritis work instability scale (RA-WIS). Ann Rheum Dis 2009;68:1686-90.

12. Gilworth G, Emery P, Gossec L, et al. Adaptation and cross-cultural validation of the RA-WIS (Work Instability Scale). Ann Rheum Dis 2009;68:1686-90.

13. Jarrett SJ, Sivera F, Cawkwell LS, et al. MRI and clinical findings in patients with ankylosing spondylitis eligible for anti-tumour necrosis factor therapy after a short course of etoricoxib. Ann Rheum Dis 2009;68:1466-9.

14. Haugeberg G, Conaghan PG, Quinn $\mathrm{M}$, et al. Bone loss in patients with active early rheumatoid arthritis: infliximab and methotrexate compared with methotrexate treatment alone. Explorative analysis from a 12-month randomised, double-blind, placebo-controlled study. Ann Rheum Dis 2009;68:1898-901.

15. Genovese MC, Breedveld FC, Emery P, et al. Safety of biological therapies following rituximab treatment in rheumatoid arthritis patients. Ann Rheum Dis 2009;68:1894-7

16. Kekow J, Moots RJ, Emery P, et al. Patient-reported outcomes improve with etanercept plus methotrexate in active early rheumatoid arthritis and the improvement is strongly associated with remission: the COMET trial. Ann Rheum Dis 2010;69:222-5

17. Furst DE, Keystone EC, Fleischmann R, et al. Updated consensus statement on biological agents for the treatment of rheumatic diseases, 2009. Ann Rheum Dis 2010;69(Suppl 1):i2-29.

18. Freeston JE, Wakefield RJ, Conaghan PG, et al. A diagnostic algorithm for persistence of very early inflammatory arthritis: the utility of power Doppler ultrasound when added to conventional assessment tools. Ann Rheum Dis 2010;69:417-9.

19. Jones $\mathbf{E}$, Churchman SM, English A, et al. Mesenchymal stem cells in rheumatoid synovium: enumeration and functional assessment in relation to synovial inflammation level. Ann Rheum Dis 2010;69:450-7.

20. Alten RE, Zerbini C, Jeka S, et al. Efficacy and safety of pamapimod in patients with active rheumatoid arthritis receiving stable methotrexate therapy. Ann Rheum Dis 2010;69:364-7.
21. Machold KP, Landewé R, Smolen JS, et al. The Stop Arthritis Very Early (SAVE) trial, an international multicentre, randomised, double-blind, placebo-controlled trial on glucocorticoids in very early arthritis. Ann Rheum Dis 2010;69:495-502.

22. Schoels M, Knevel R, Aletaha D, et al. Evidence for treating rheumatoid arthritis to target: results of a systematic literature search. Ann Rheum Dis 2010;69:638-43.

23. Smolen JS, Aletaha D, Bijlsma JW, et al.; T2T Expert Committee. Treating rheumatoid arthritis to target: recommendations of an international task force. Ann Rheum Dis 2010;69:631-7.

24. Burr ML, Naseem H, Hinks A, et al.; BIRAC Consortium; YEAR Consortium. PADI4 genotype is not associated with rheumatoid arthritis in a large UK Caucasian population. Ann Rheum Dis 2010;69:666-70.

25. Emery $\mathbf{P}$, Durez P, Dougados $\mathrm{M}$, et al. Impact of T-cell costimulation modulation in patients with undifferentiated inflammatory arthritis or very early rheumatoid arthritis: a clinical and imaging study of abatacept (the ADJUST trial). Ann Rheum Dis 2010;69:510-16.

26. Bennett AN, Rehman A, Hensor EM, et al. The fatty Romanus lesion: a noninflammatory spinal MRI lesion specific for axial spondyloarthropathy. Ann Rheum Dis 2010;69:891-4.

27. Nam JL, Winthrop KL, van Vollenhoven RF, et al. Current evidence for the management of rheumatoid arthritis with biological disease-modifying antirheumatic drugs: a systematic literature review informing the EULAR recommendations for the management of RA. Ann Rheum Dis 2010;69:976-86.

28. Smolen JS, Landewé R, Breedveld FC, et al. EULAR recommendations for the management of rheumatoid arthritis with synthetic and biological disease-modifying antirheumatic drugs. Ann Rheum Dis 2010;69:964-75.

29. Tan RJ, Gibbons LJ, Potter C, et al.; BRAGGSS. Investigation of rheumatoid arthritis susceptibility genes identifies association of AFF3 and CD226 variants with response to anti-tumour necrosis factor treatment. Ann Rheum Dis 2010;69:1029-35.

30. Robinson JI, Barrett JH, Taylor JC, et al.; YEAR Consortium; BRAGGSS. Dissection of the FCGR3A association with RA: increased association in men and with autoantibody positive disease. Ann Rheum Dis 2010;69:1054-7.

31. Cohen SB, Keystone E, Genovese MC, et al. Continued inhibition of structural damage over 2 years in patients with rheumatoid arthritis treated with rituximab in combination with methotrexate. Ann Rheum Dis 2010;69:1158-61.

32. Haugeberg G, Bennett AN, McGonagle D, et al. Bone loss in very early inflammatory back pain in undifferentiated spondyloarthropathy: a 1-year observational study. Ann Rheum Dis 2010;69:1364-6.

33. Schoels M, Aletaha D, Smolen JS, et al. Follow-up standards and treatment targets in rheumatoid arthritis: results of a questionnaire at the EULAR 2008. Ann Rheum Dis 2010;69:575-8

34. Eyre S, Flynn E, Martin P, et al. No evidence for association of the KLF12 gene with rheumatoid arthritis in a large UK cohort. Ann Rheum Dis 2010;69:1407-8.

35. Eyre S, Hinks A, Flynn E, et al. Confirmation of association of the REL locus with rheumatoid arthritis susceptibility in the UK population. Ann Rheum Dis 2010;69:1572-3

36. Orozco G, Eyre S, Hinks A, et al.; Wellcome Trust Case Control consortium YEAR Consortium. Association of CD40 with rheumatoid arthritis confirmed in a large UK case-control study. Ann Rheum Dis 2010;69:813-16.

37. Emery $\mathbf{P}$, Durez P, Dougados $M$, et al. Impact of T-cell costimulation modulation in patients with undifferentiated inflammatory arthritis or very early rheumatoid arthritis: a clinical and imaging study of abatacept (the ADJUST trial). Ann Rheum Dis 2010;69:510-16

38. Saleem B, Keen $\mathrm{H}$, Goeb V, et al. Patients with RA in remission on TNF blockers: when and in whom can TNF blocker therapy be stopped? Ann Rheum Dis 2010;69:1636-42.

39. Barkham N, Coates LC, Keen H, et al. Double-blind placebo-controlled trial of etanercept in the prevention of work disability in ankylosing spondylitis. Ann Rheum Dis 2010;69:1926-8.

40. Emery P, Deodhar A, Rigby WF, et al. Efficacy and safety of different doses and retreatment of rituximab: a randomised, placebo-controlled trial in patients who are biological naive with active rheumatoid arthritis and an inadequate response to methotrexate (Study Evaluating Rituximab's Efficacy in MTX iNadequate rEsponders (SERENE)). Ann Rheum Dis 2010;69:1629-35.

41. Dixon WG, Hyrich KL, Watson KD, et al.; BSRBR Control Centre Consortium; British Society for Rheumatology Biologics Register. Influence of anti-TNF therapy on mortality in patients with rheumatoid arthritis-associated interstitial lung disease: results from the British Society for Rheumatology Biologics Register. Ann Rheum Dis 2010;69:1086-91. 